\title{
THE ELBOW IN ARTHROGRYPOSIS
}

\author{
Peter F. Williams, Melbourne, Australia \\ Chief Orthopaedic Surgeon, Royal Children's Hospital, Melbourne
}

Over 100 cases of arthrogryposis have been seen at the Royal Children's Hospital in Melbourne in the past fifteen years and most of the patients are still under our care.

This condition, which is characterised by multiple rigid joint deformities, occurs in families with an impeccable genetic background and there is no evidence of hereditary causation. The infants are born to young and older mothers alike. Extrinsic factors seem to play no part.

The extent of affection varies from one or two joints to almost total involvement. Even the joints of the spine and the mandible may be implicated. Occasionally there is associated webbing or dislocation of involved joints, and spina bifida cystica may also be present.

The nature of the affliction is not well understood but it is essential to appreciate the pathology in order to plan a logical scheme of treatment.

\section{PATHOLOGY}

Only those features of the pathology which are relevant to the treatment will be discussed.

Firstly, in the affected joints the actual articulation is normal or nearly so at birth and remains so for a number of years. The obstruction to movement is almost wholly extraarticular, and when this is freed the joint moves through a nearly normal range. The only exception to this rule is the foot, for in many cases the joints around the talus are poorly formed, have intra-articular adhesions and can be mobilised only by operations on bone such as talectomy.

The muscles in arthrogryposis vary a great deal. One muscle may be of normal size and colour while an adjacent one may be small, pale and contracted or completely absent. Sometimes, as is common at the elbow, a whole muscle compartment will be absent-for example, biceps and brachialis. When muscles are small or absent there may be striking hypertrophy of subcutaneous fat so that the bulk of the limb is largely preserved. On exploration of such a limb the surgeon may be surprised to find only a neurovascular bundle and no evidence of muscular tissue.

Ligaments and capsules are always found to be contracted in affected joints and it is not clear whether this is primary or secondary to the muscle atrophy. Each joint has a characteristic finding: for example, in the stiff extended knee the patella is frozen to the front of the femur, and at the elbow the olecranon is bound down by the capsule to the back of the humerus. The strength and density of these contractures is such that stretching is unlikely to succeed and operation for release may be indicated. Serial stretching or plastering is not only likely to be ineffective but it almost certainly causes harm by producing pressure necrosis of articular cartilage.

The principles of treatment therefore consist of: 1) early release by operation; 2) tendon transfer when possible, to replace absent or ineffective muscles; and 3) prolonged physiotherapy or splinting to maintain correction.

\section{ELBOW INVOLVEMENT IN ARTHROGRYPOSIS}

There are two major types and various intermediate grades of elbow involvement.

The first type is the elbow which is stiff in flexion. Here the elbow usually has a useful range around the right angle position. Biceps is strong and triceps often weak or absent. 
It has not been found necessary to treat any of this type because they have good function and there does not seem to be any simple way of improving this. A typical case is shown in Figure 1, and Figure 2 shows how a crutch can easily be adapted to the flexed elbow.

The second and more important type is the elbow which is stiff in extension. Here the joint is usually rigid in full extension, with only a rock of movement; but occasionally there

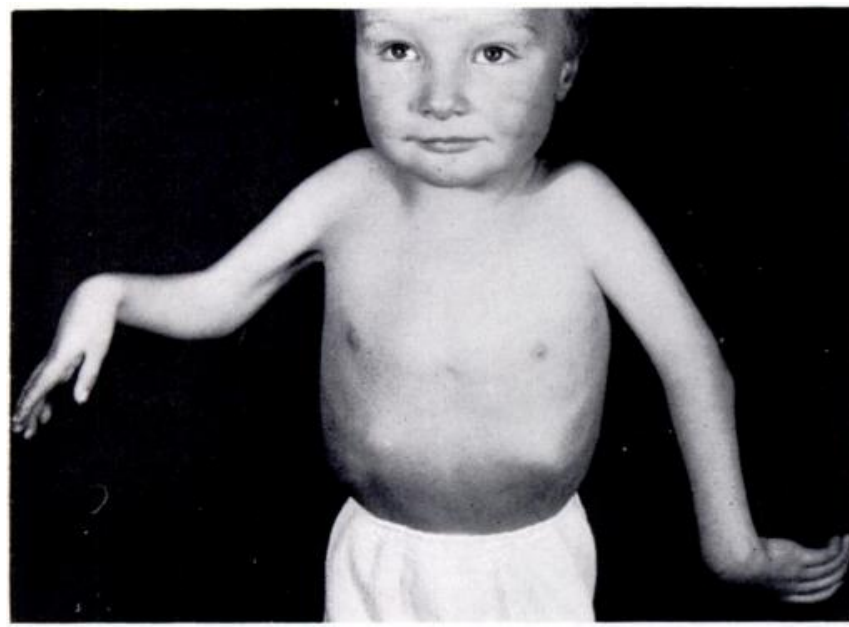

Fig. 1

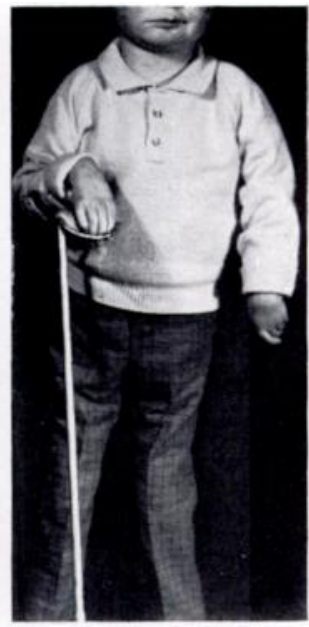

FIG. 2

Figure 1-The right elbow has a typical flexion deformity. Figure 2-The same boy at the age of 5 years, using a crutch modified for the flexed elbow.

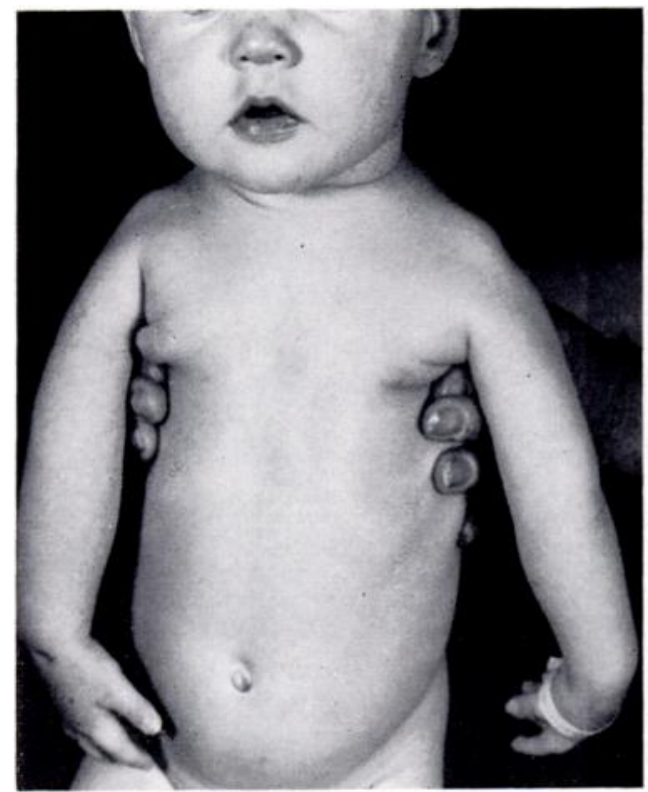

FIG. 3

A typical example of extended elbows. There is also medial rotation at the shoulder, flexion at the wrist and various finger deformities.

may be up to 30 degrees of flexion. The triceps is always strong and the biceps and brachialis are usually absent. In most of these children the wrist is rigidly flexed, the forearm is pronated 


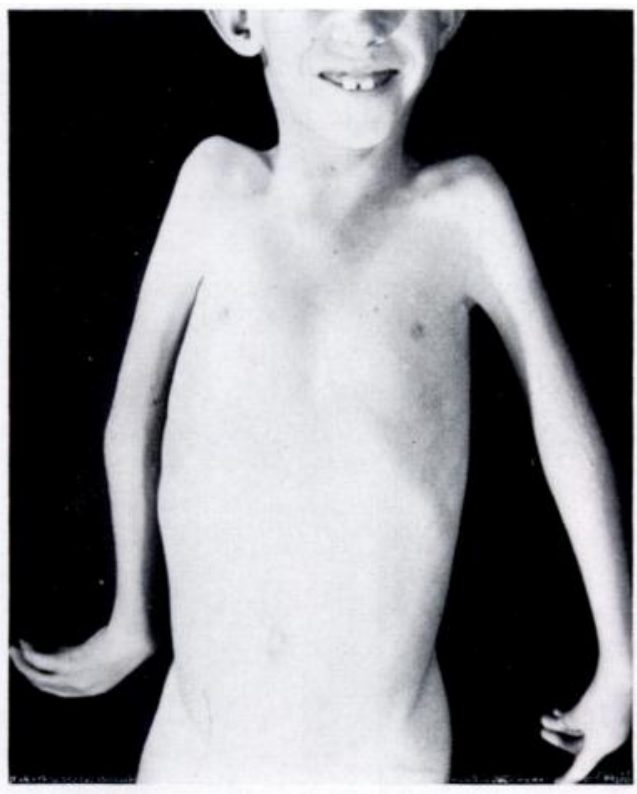

Fig. 4

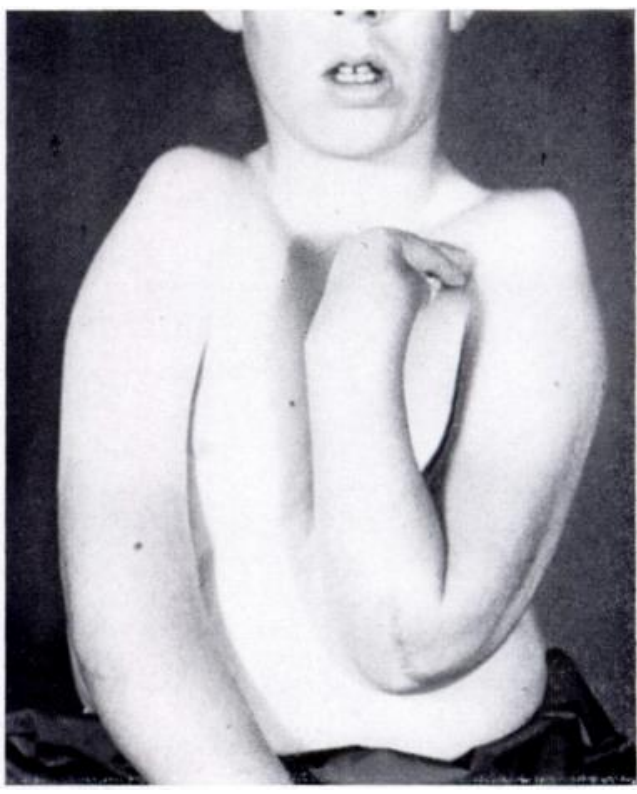

FIG. 5

Figure 4-A 12-year-old boy with elbows rigid in extension. Figure 5-The same boy after mobilisation of both elbows and triceps transfers. Now able to feed himself, he has gained 2 stone ( $12 \cdot 7$ kilograms) in weight over several months since operation.

and one or more fingers have stiff interphalangeal joints. The forearm flexors may be present as well (Fig. 3). All this represents a severe disability, especially in bilateral cases, for while the arms are ideally suited for crutch walking, the hands cannot reach the mouth for feeding.

Figure 4 illustrates a twelve-year-old boy who had two rigid elbows and had been fed by his mother all his life. On the basis of three meals a day this represented a total of 13,500

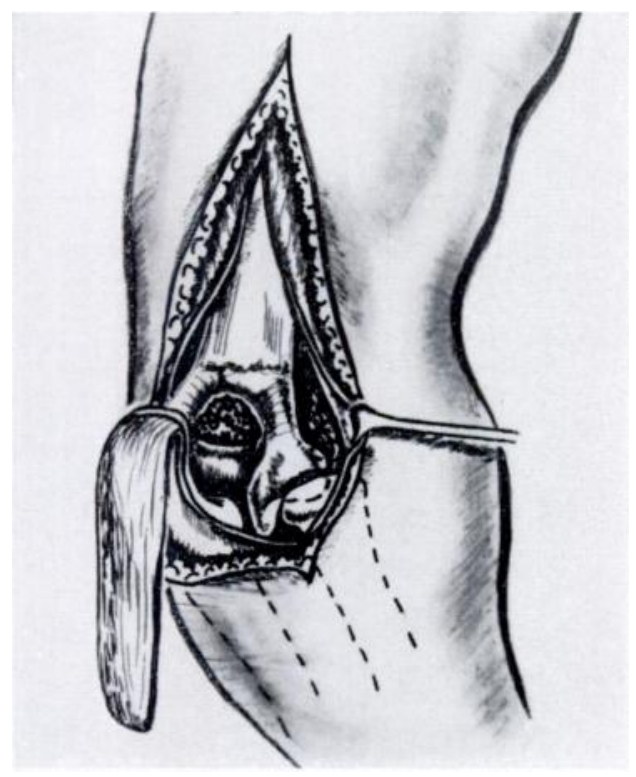

FIG. 6

Simple tricepsplasty. feedings. His mother had almost reached the limit of human endurance. Both elbows have recently been mobilised and the triceps moved forwards. Each now has an almost full range of movement and there is sufficient power for self-feeding (Fig. 5). The result has been a complete change in personality and a gain of two stone in weight.

As regards operation in general it can be said that if the lower limbs are not involved and there is no possibility of the child depending on crutch walking, there should be no hesitation in mobilising the elbows at an early age. In children over two years old, the various operative procedures are technically easy to perform and may be done in a bloodless field.

There may be some advantage in postponing treatment until the child is old enough to cooperate in the post-operative physiotherapy. If the lower limbs are involved, treatment of the arms should be deferred at least until the child is agile on crutches. 


\section{OPERATIONS ON THE ELBOW}

There are five types of operation: 1) simple tricepsplasty-that is, lengthening of the triceps tendon and posterior release of the elbow: 2) triceps transfer-this has been described

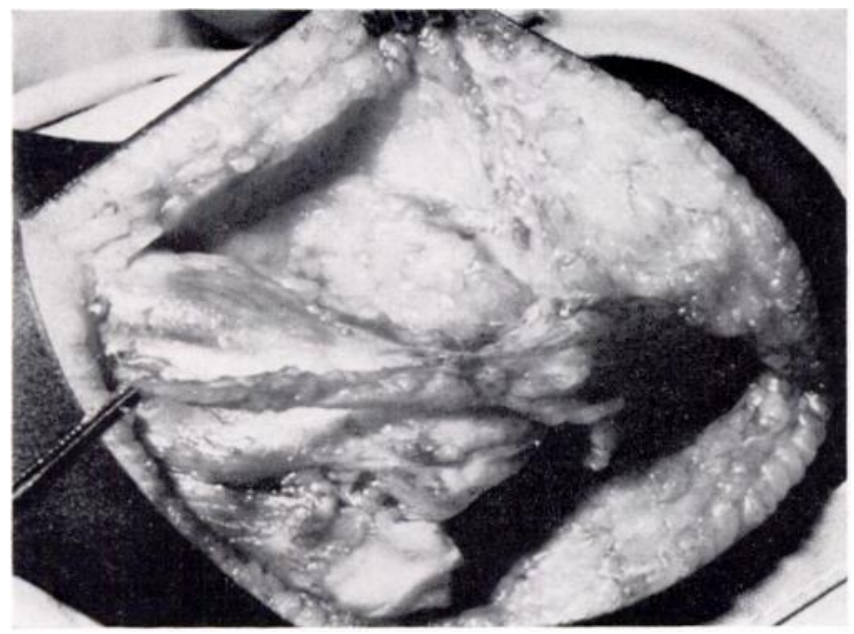

Fig. 7

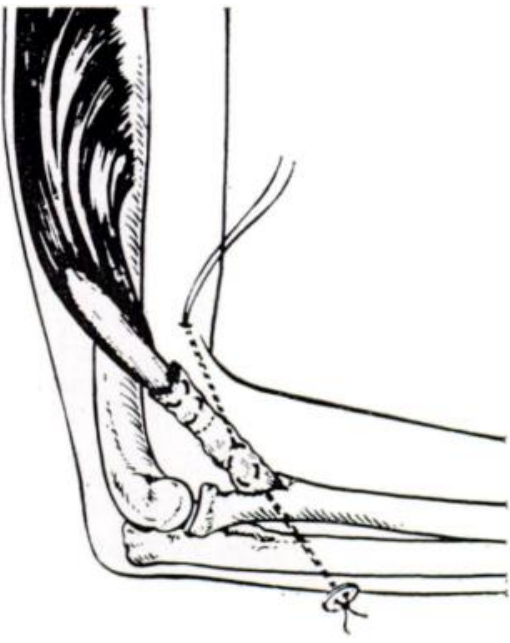

FIG. 8

Figure 7-Photograph at operation showing the triceps removed from the olecranon together with a periosteal prolongation. Figure 8 -Triceps transfer to the radius (or ulna).

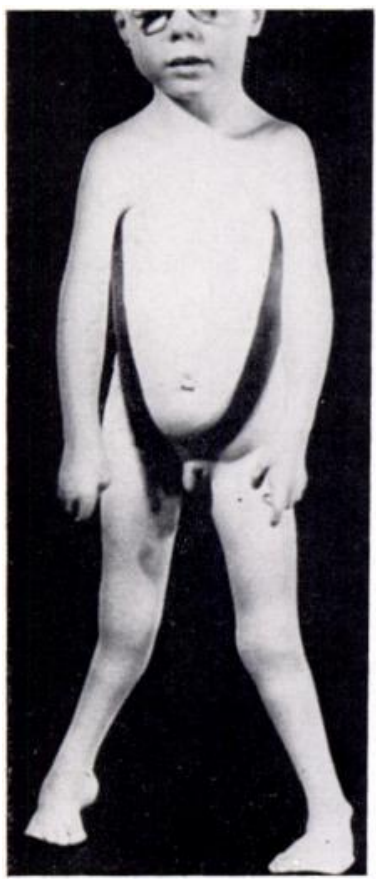

Fig. 9

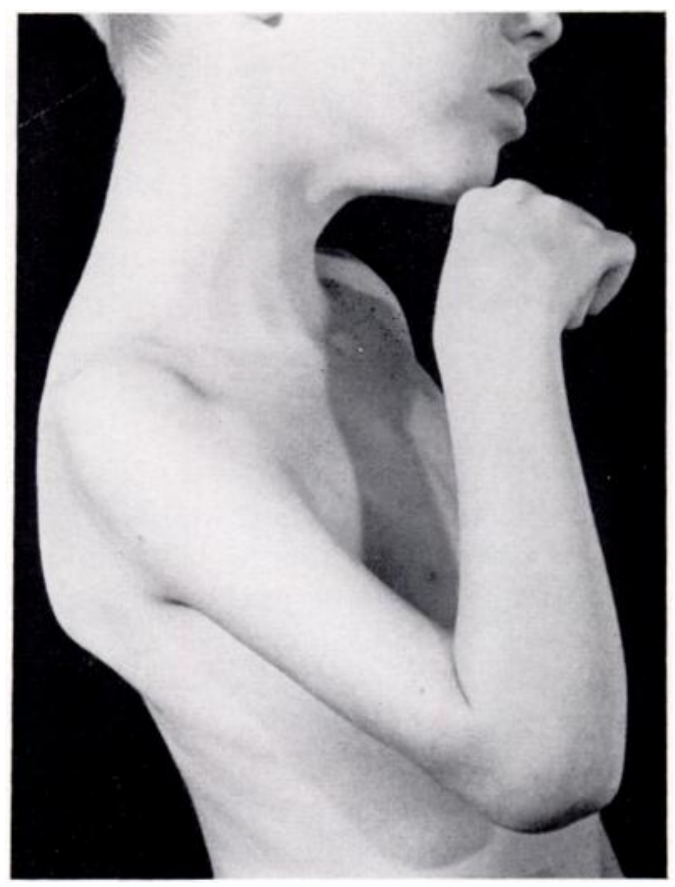

FIG. 10

Figure 9-A 5-year-old boy with relapsed club feet and extended elbows. Figure 10After triceps transfers both elbows have a range of 60 degrees and flexor power is strong.

by Bunnell (1951) and Carroll (1952) and is, of course, always combined with posterior release of the elbow joint; 3 ) tricepsplasty and Steindler flexorplasty-the former supplies mobility VOL. 55 B, NO. 4, NOVEMBER 1973 
and the latter the flexor motor; 4) pectoralis major transfer; 5) sternomastoid transfer. These methods will now be considered in more detail.

Tricepsplasty-The triceps tendon is lengthened using a standard V-Y technique and the olecranon freed from the back of the humerus (Fig. 6). It may be necessary as part of this release to divide the collateral ligaments of the elbow and open up the back of the radiohumeral joint. The ulnar nerve can be removed from its sheath and allowed to prolapse forwards. If it is done when the child is young the procedure can be relied upon to give a range of at least 90 degrees and to permit retention of useful triceps action. Immobilisation is needed for only three weeks after operation. Then, physiotherapy is started. This procedure is not often indicated and should only be carried out when it is considered essential that triceps action must be preserved or when the elbow flexors are already present. It may, however, be used on occasions as a first stage to mobilise an elbow with a view to proceeding to triceps transfer at a later date. This two-stage operation is wise in those very skinny arms which do not retain their movement as well as do the arms which are well covered with fat. No explanation is offered for this phenomenon; it is simply an observation based on experience.

Triceps transfer-When the triceps tendon is to be transferred forward, it is dissected off the olecranon together with a tongue of periosteum from the upper shaft of the ulna (Fig. 7). The elbow joint is mobilised as before. After the triceps muscle has been mobilised up to about the middle of the arm, the tendon and its periosteal prolongation is rolled into a tube and held in that shape by a few silk sutures. This tube is then brought around the outer side of the arm superficial to the radial nerve and passed through a drill hole in the radius or ulna one inch or more below the elbow joint, and is secured here under tension with the elbow almost fully flexed (Fig. 8).

This is the operation of choice in all cases unless the forearm flexors are strong. In a successful case the child will have active elbow flexion against gravity and resistance (Figs. 9 and 10). There will usually be restriction of extension much beyond the right angle because of a tenodesis effect of the triceps.

Tricepsplasty and Steindler flexorplasty-If the forearm flexors are strong it is preferable to give them the ability to act as elbow flexors and to retain triceps action by simple elongation of its tendon. Both procedures can easily be carried out through a medial incision. The elbow will then have both flexor and extensor motors. The best results occur in those elbows which have full motion with absence of the biceps only.

Two other transfers are worth mentioning although neither has been used personally by the author in these cases.

Pectoralis major transfer-This transfer may be indicated when the forearm flexors are not available and it is desirable to have both flexion and extension motors. The disadvantage lies in the fact that, because no biceps tendon is present, the full Clark (1946) operation using the rectus sheath to lengthen the transferred muscle is needed, and this leaves a very long and unsightly scar.

Sternomastoid transfer-The operation described by Bunnell (1951) would have questionable chances of success because of the need for an excessively long fascial tube.

\section{RESULTS}

The experience gained in this problem was obtained from the study of twenty children, each of whom had bilateral elbow involvement. In eight of these the upper limbs only were affected whereas the remainder were fairly typical cases of arthrogryposis multiplex. It is of some interest that two children out of the eight with arm involvement had absence of the tibialis anterior muscles in each leg.

Table I sets out the details of the treatment of the twenty-three of the forty elbows studied. Six children have had operations on both elbows, either a release and a transfer or two 
transfers. Four children are awaiting operations on the other side. Two were rejected for operation because the elbows were flail and two spontaneously though slowly developed both movement and biceps action. All the children under review have been examined recently and the range of movement and power have been assessed by an independent physiotherapist. The remainder are mostly undergoing operations for lower limb deformities or dislocations and elbow surgery has been deferred until this is completed.

Table II shows the range of movement in the four elbows submitted to tricepsplasty. The results show a useful range around the right angle. The arc obtained bore little or no relationship to the age at the time of operation. Table III shows the power and range of movement after tricepsplasty and transfer.

TABLE I

OPERATIONS

\begin{tabular}{|lcc|}
\hline Operation & & $\begin{array}{c}\text { Number of } \\
\text { elbows }\end{array}$ \\
\hline Tricepsplasty $\cdot \cdot \cdot$ & $\cdot$ & 4 \\
Tricepsplasty and triceps transfer & 19 \\
\hline
\end{tabular}

TABLE II

RANGE OF MOVEMENT AFTER TRICEPSPLASTY

\begin{tabular}{|ccc|}
\hline \multirow{2}{*}{$\begin{array}{c}\text { Case } \\
\text { number }\end{array}$} & \multicolumn{2}{c|}{ Movement (degrees) } \\
\hline 1 & Before operation & After operation \\
\hline 7 & $30-90$ & $40-110$ \\
10 & $0-5$ & $50-100$ \\
14 & $0-5$ & $60-100$ \\
\hline
\end{tabular}

The average age at time of operation was a little over six years with a spread from ten months to thirteen years. The average follow-up period of all cases was four years and nine months.

\section{ASSESSMENT OF FUNCTIONAL IMPROVEMENT}

It is very difficult if not impossible to set out in a scientific manner the results of this type of surgery. However, it can be said that all patients have been improved. After the first elbow has been treated the parents invariably ask for a similar procedure to be done on the other side.

The following note taken from the clinical record of one child is a good summary of the situation: "The mother is delighted with the operative measures. She realises that the child has little strength in the arms but says that the increased mobility of her arms has been very successful in allowing her to be independent. For example, the child can now dress herself and do up her own buttons, etc."

It is not clear why the results in terms of power are so variable, especially as the preoperative assessment of the triceps power invariably showed normal strength and the operations have all been performed by a single surgeon using a standard technique. Surprisingly, the younger age group had the higher incidence of weak transfers, and this may be related to their inability to co-operate with re-education. The age group four to six years seems to 
offer the best opportunity for a good result. Nevertheless, despite this great variability, operation has produced greatly increased function in every case.

This paper must be regarded as a preliminary report on a much neglected subject and it is hoped that experience will improve the quality of the results. Our results so far are most encouraging.

TABLE III

Power AND RANGe AFTer TricepsPlasty AND TRANSFER

\begin{tabular}{|c|c|c|c|}
\hline \multirow{2}{*}{$\begin{array}{c}\text { Case } \\
\text { number }\end{array}$} & \multicolumn{2}{|c|}{ Range of movement (degrees) } & \multirow{2}{*}{$\begin{array}{c}\text { Power } \\
\text { (M.R.C. Grade) }\end{array}$} \\
\hline & Before operation & After operation & \\
\hline 1 & $0-\quad 5$ & $100-135$ & 5 \\
\hline 2 & $0-40$ & $40-140$ & 5 \\
\hline 3 & $0-20$ & $45-100$ & 2 \\
\hline 5 & $0-80$ & $90-110$ & 5 \\
\hline 6 & $0-20$ & $45-95$ & 5 \\
\hline 7 & $0-5$ & $60-80$ & 0 \\
\hline 8 & $\begin{array}{ll}0- & 5 \\
0- & 5\end{array}$ & $\begin{array}{l}45-110 \\
60-110\end{array}$ & $\begin{array}{l}2 \\
3\end{array}$ \\
\hline 9 & $\begin{array}{l}0-80 \\
0-90\end{array}$ & $\begin{array}{l}90-145 \\
90-120\end{array}$ & $\begin{array}{l}4+ \\
4+\end{array}$ \\
\hline 11 & $\begin{array}{l}0-90 \\
0-90\end{array}$ & $\begin{array}{l}80-110 \\
70-120\end{array}$ & $\begin{array}{l}5 \\
5\end{array}$ \\
\hline 12 & $\begin{array}{l}0-85 \\
0-100\end{array}$ & $\begin{array}{l}10-100 \\
35-130\end{array}$ & $\begin{array}{l}5 \\
5\end{array}$ \\
\hline 14 & $0-5$ & $50-100$ & $2+$ \\
\hline 15 & $\begin{array}{ll}0- & 5 \\
0- & 5\end{array}$ & $\begin{array}{l}30-110 \\
55-130\end{array}$ & $\begin{array}{l}4+ \\
2\end{array}$ \\
\hline 16 & $30-100$ & $60-110$ & 5 \\
\hline 17 & 0-90 & $80-135$ & 3 \\
\hline
\end{tabular}

\section{SUMMARY}

1. The possibilities in the treatment of the elbow in arthrogryposis are discussed.

2. The role of tricepsplasty to gain movement, and of triceps transfer to obtain power are outlined and the results obtained in the surgical treatment of twenty-three elbows are analysed.

\section{REFERENCES}

Bunnell, S. (1951): Restoring Flexion to the Paralytic Elbow. Journal of Bone and Joint Surgery, 33-A, 566. Carroll, R. E. (1952): Restoration of Flexor Power to the Flail Elbow by Transplantation of the Triceps Tendon. Surgery, Gynecology and Obstetrics, 95, 685.

Clark, J. M. P. (1946): Reconstruction of Biceps Brachii by Pectoral Muscle Transplantation. British Journal of Surgery, 34, 180. 